\title{
AN EVALUATION OF SOME ELEMENTS OF SAFETY OF THE INTERNAL AND EXTERNAL ENVIRONMENT IN WHICH CHILDREN IN PORT SAID CITY KINDERGARTENS LIVE IN THE LIGHT OF QUALITY CRITERIA.
}

Abd- ElHafez, Nabila E.

Home and Institution Management DepT., Suez Canal University

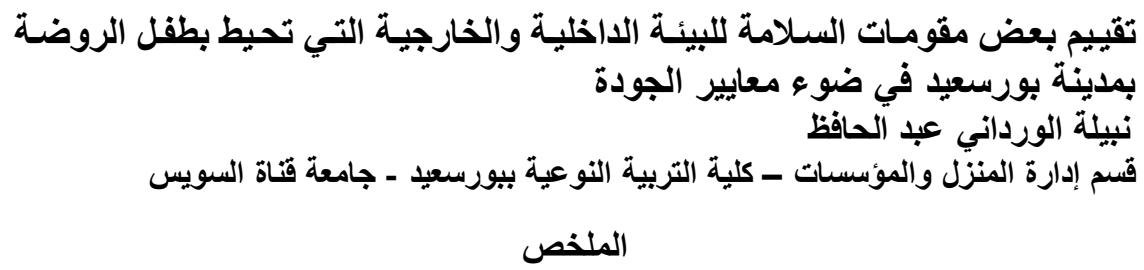

\section{المقدمة والمشكلة البحثية}

لاقت مرحلة الطفولة اهتماما عالميا منذ بداية النصف الثاني من القرن الماضي مما دعا هيئة الأمم

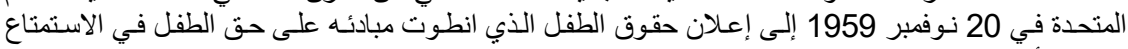

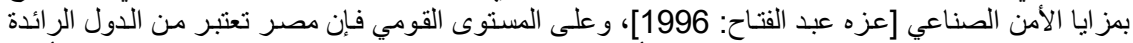

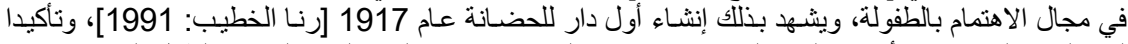

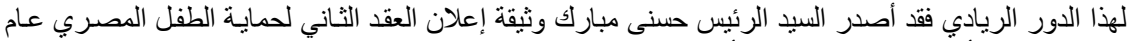

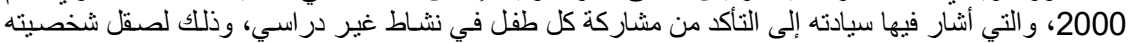

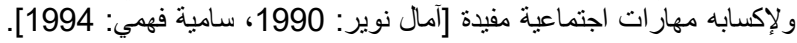


Abd- ElHafez, Nabila E.

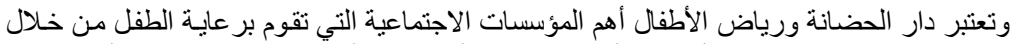

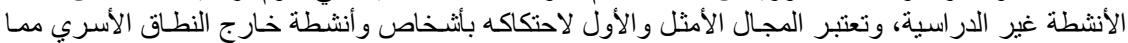

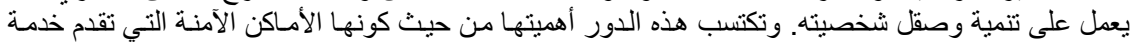

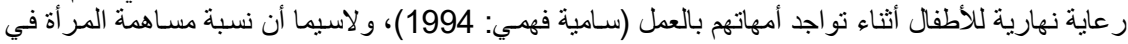

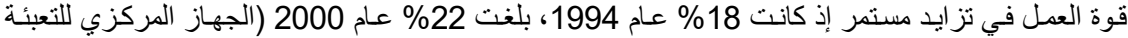

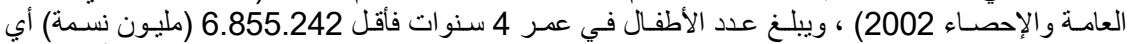

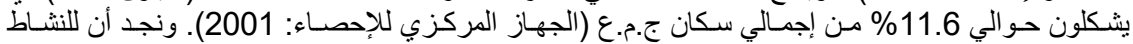

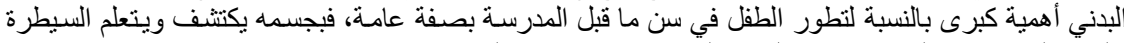

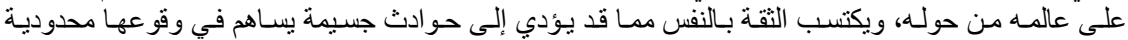

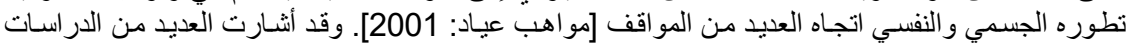

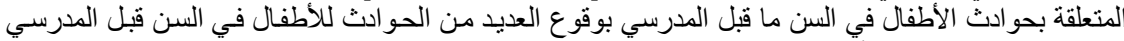

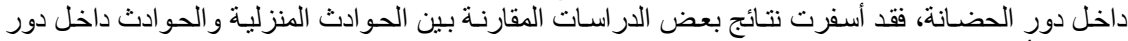

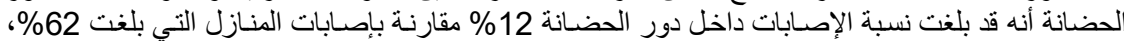

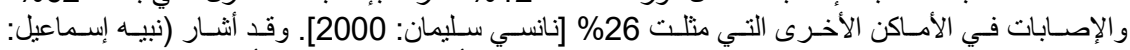

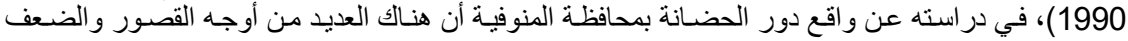

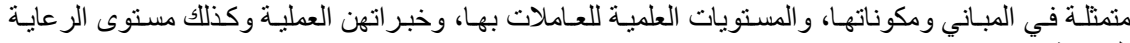

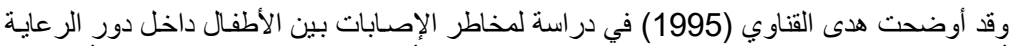
الصحية.

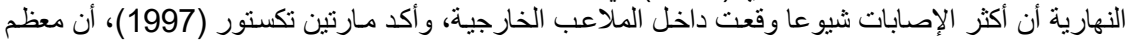

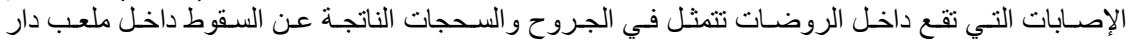

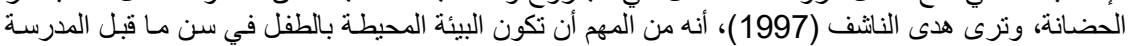

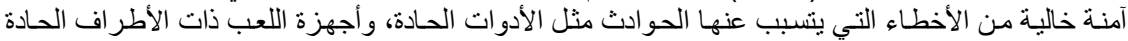

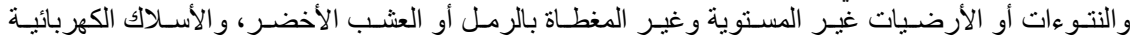

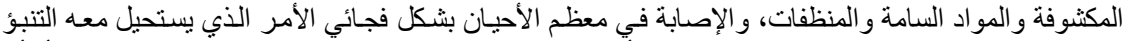

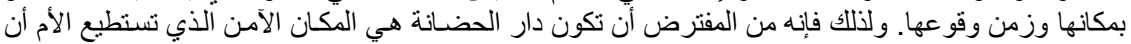

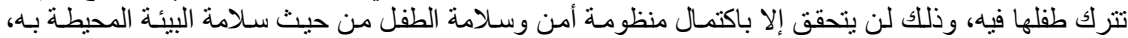

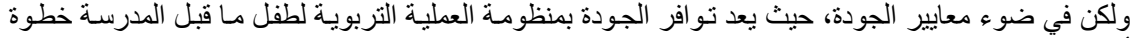

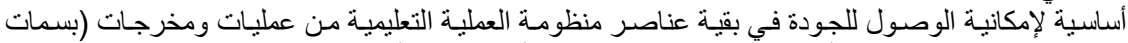

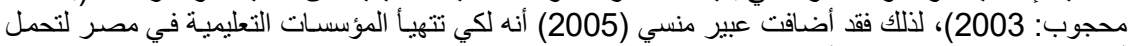

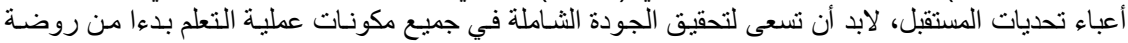

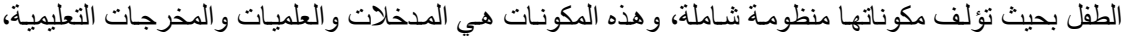

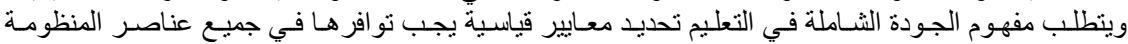

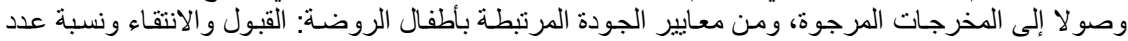

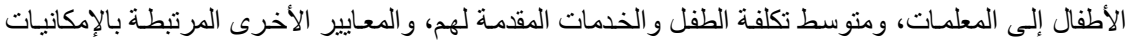

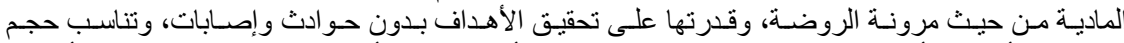

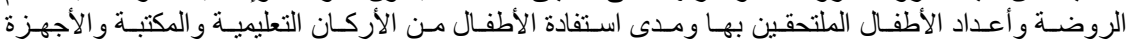

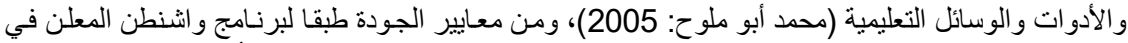

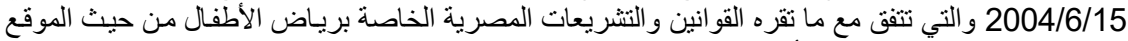

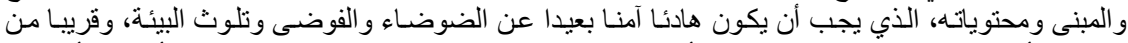

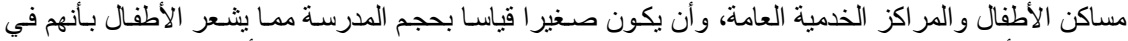

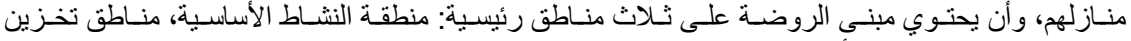

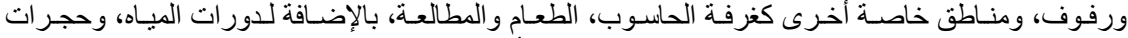

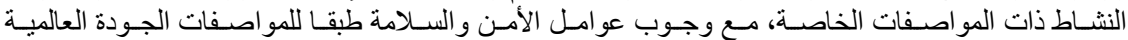

(National Association: 2004)

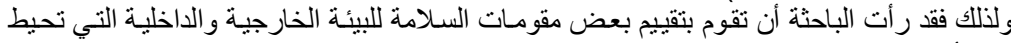
بأطفال رياض الأطفال بمدينة بورسعيد في ضوء لبمدة معايير الجودة. 
تمثل الهلف الرئيسي للبحث في تقييم بعض مقومـات السلامة للبيئة الخارجية والاخلية المحيطة

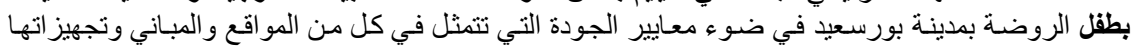

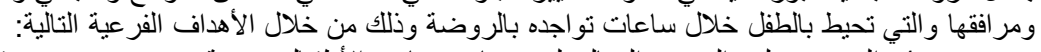

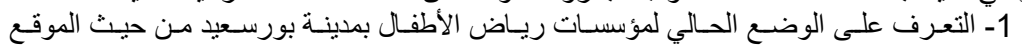

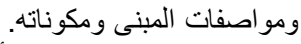
2- التعرف على أركان النشاط و الغرف ومحتوياتها. 3- التعرف على الوضع الحنالي لدنـاطق الخدمات و الحدائق و الملاعب داخل مؤسسات ريـاض 4- استخلاص بعض التوصيات التي قد تؤدي إلى تفعيل وتطبيق عناصر الجودة المنصوص عليها في العملية التربوية و التعليمية والخاصة بمرحلة رياض الأطفال.

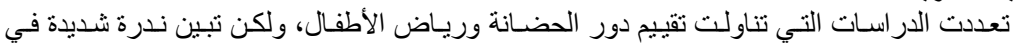

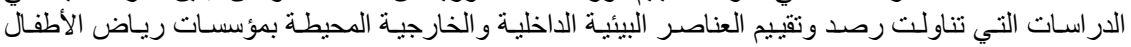

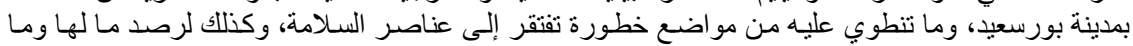

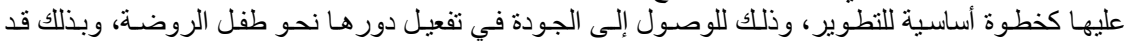

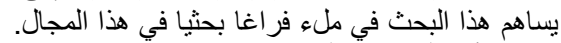

ثانيا: الأهمية التطبيقية:

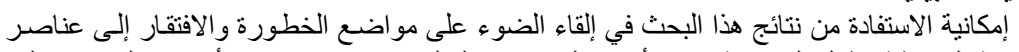

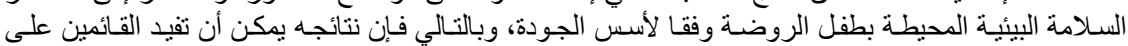

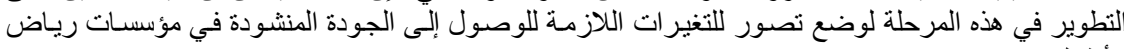

الأطفال.

مصطلحات الاراسة:

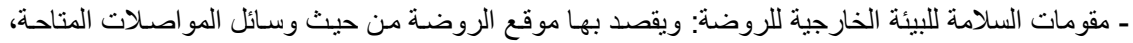

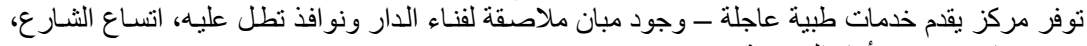

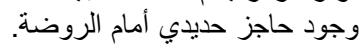

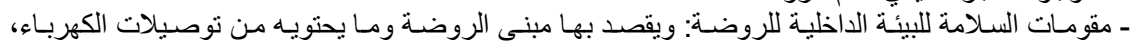

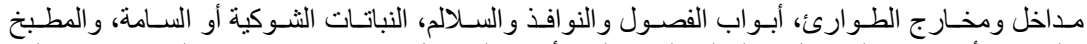

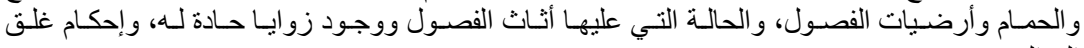
الدو اليب.

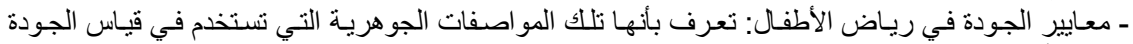

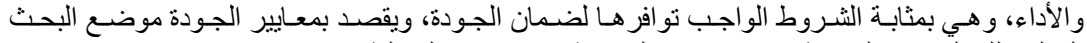

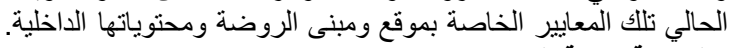
حدود الاراسة: عينة البحث:

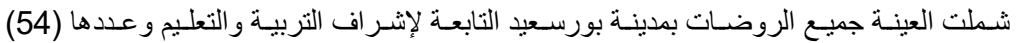

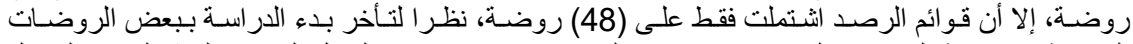

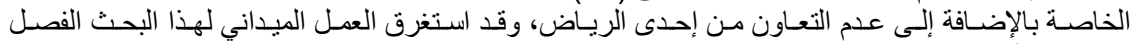
الدراسي الأول للعام الدراسي جدول (1) عدد دور الحضانة بمدينة بورسعيد الأري

\begin{tabular}{|c|c|c|c|c|c|c|c|}
\hline المجموع & شرق & المناح & الزهور & الضواحي & بور فؤاد & العرب & الكعد \\
\hline $\begin{array}{l}25 \\
77\end{array}$ & - & 2 & 16 & 4 & 3 & - & دور الحضانة التابعة للحمعيات \\
\hline
\end{tabular}

المصدر : مديرية الثئون الاجتماعية - بور النية سعبد 2004 جدول (2) عدد الروضات بمحافظة بورسئيد بأنواعيد اعها للعام الدراسي 2004 - 2005 
Abd- ElHafez, Nabila E.

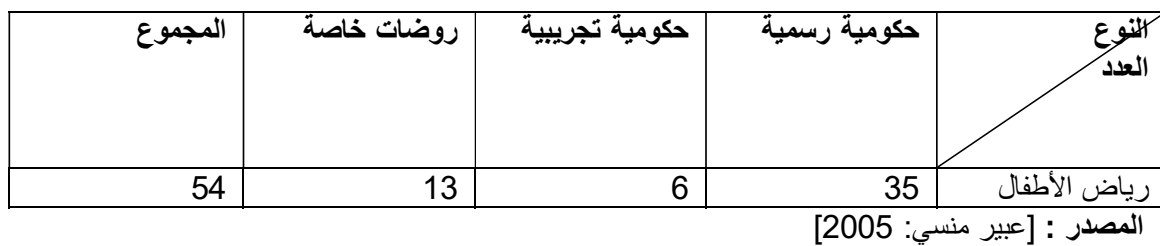

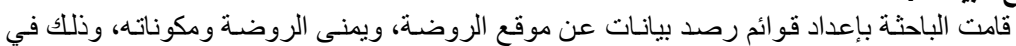

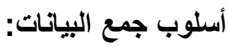

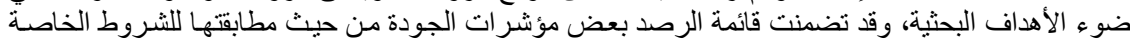

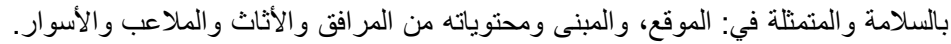

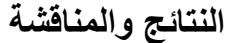

أولا: بيانات تتعلق بموقع الروضة:

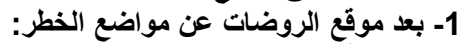

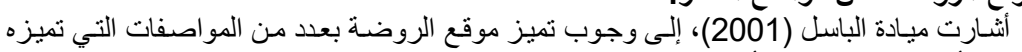

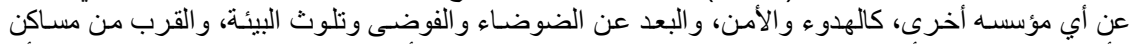

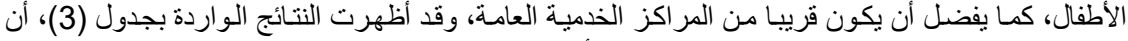

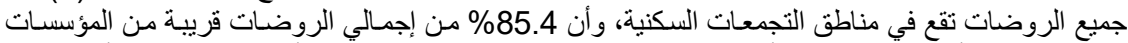

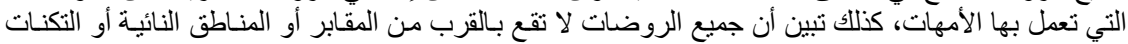

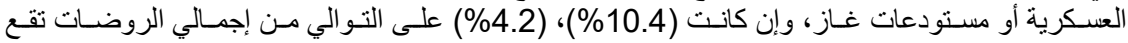

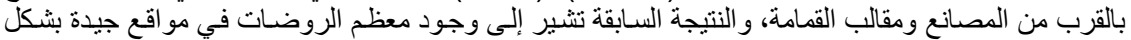

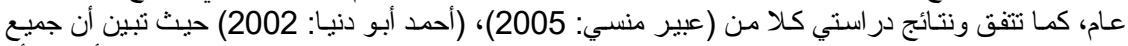

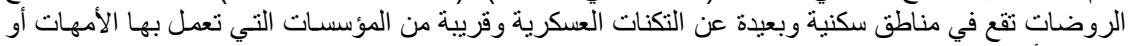

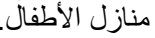

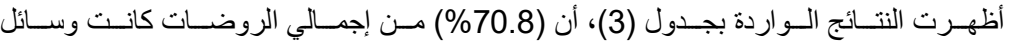

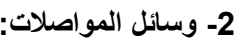

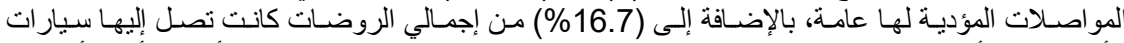

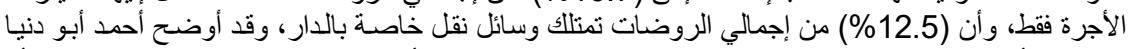

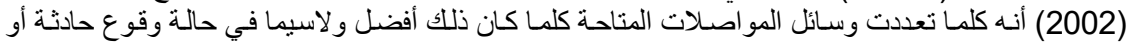

إصابة.

3- 3- أقرب مركز يقدم خدمات طبية:

يتبين من نتائج الدراسة الو اردة بجدول (3)، أن المستوصفات قد احتلت المركز الأول من القرب التوبت

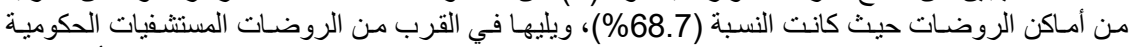

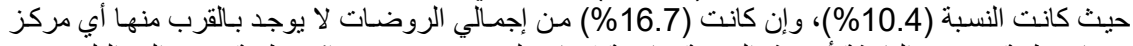

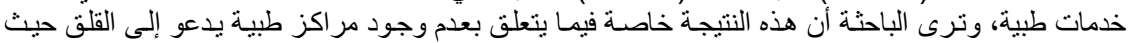

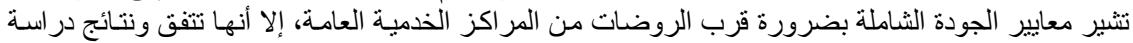

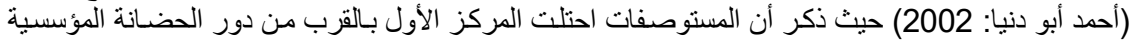
والخاصة بمدينة الإسكندرية.

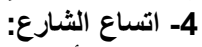

أظهرت النتائج الواردة بجدول (3) أن (87.5\%) من من الروضـات تقع في شـوارع متسعة، بينما

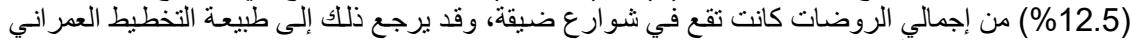

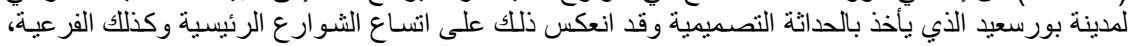
و المبادين العامة، وهذا يتماثى مع بنود اللوائح النموذجية لرياض الأطفال ومعايير الجودة الثناملة حيث يفضل التهل 
أن يتصـل موقع الحضـانة بـالطريق العـام المتسـع لتيسير وصـول سيارات الإسـعاف و الإطفـاء إن احتـاج الأمـر

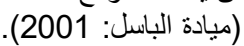

جدول (3): توزيع الروضات بمدينة بورسعيد طبقا لبعض المواصفات المتعقة بموقع الروضة

\begin{tabular}{|c|c|c|}
\hline$\%$ & العدد & المواصفات \\
\hline $\begin{array}{c}100 \\
85.4 \\
10.4 \\
4.2 \\
\end{array}$ & $\begin{array}{c}48 \\
41 \\
5 \\
2 \\
\end{array}$ & 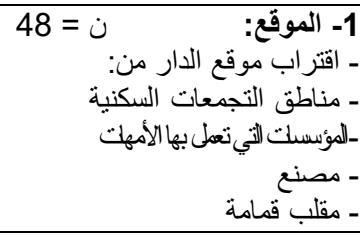 \\
\hline $\begin{array}{l}70.8 \\
16.7 \\
12.5\end{array}$ & $\begin{array}{c}34 \\
8 \\
6\end{array}$ & 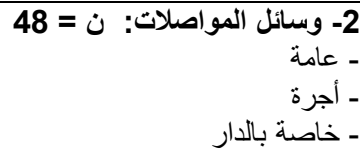 \\
\hline 100 & 48 & مجموع \\
\hline $\begin{array}{c}10.4 \\
4.2 \\
68.7 \\
16.7\end{array}$ & $\begin{array}{c}5 \\
2 \\
33 \\
8\end{array}$ & 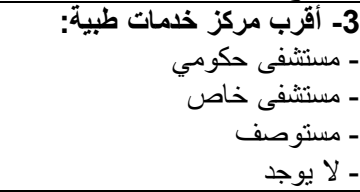 \\
\hline 100.0 & 48 & مجموع \\
\hline $\begin{array}{l}87.5 \\
12.5\end{array}$ & $\begin{array}{c}42 \\
6\end{array}$ & - - متسع اتساع الثـارع: \\
\hline 100 & 48 & مجموع \\
\hline
\end{tabular}

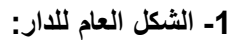

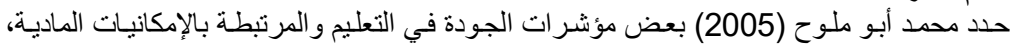

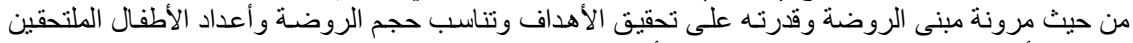

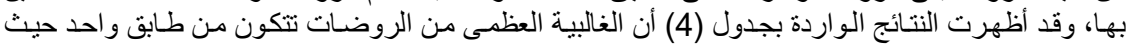

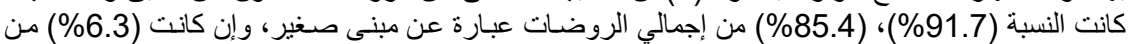

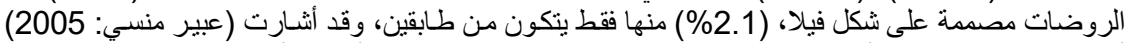

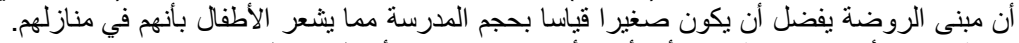

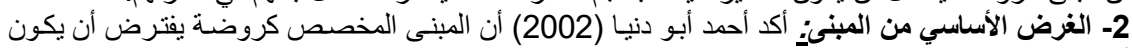

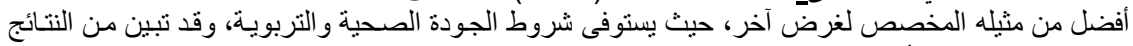

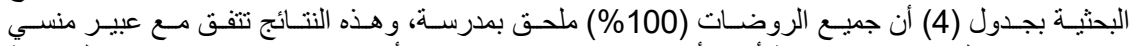

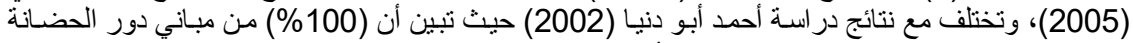

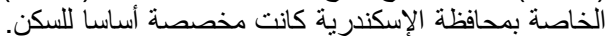
3- تواجد السور وألوانه:

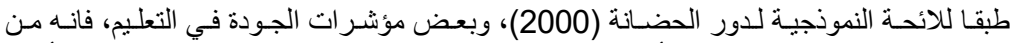

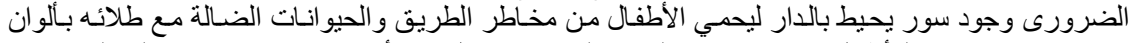

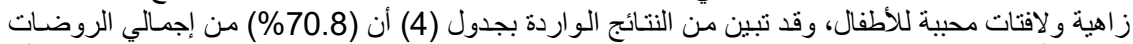

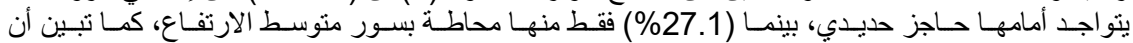

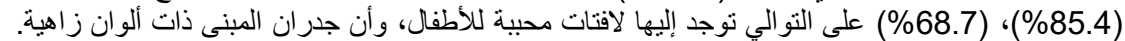
جدول (4): توزيع الروضات بمدينة بورسعيد طبقا لبعض الموات التفات العامة للمبنى:

\begin{tabular}{|c|c|c|c|}
\hline \multirow[t]{2}{*}{$\%$} & 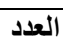 & \multicolumn{2}{|r|}{ المواصفات } \\
\hline & & $48=\dot{0}$ & 1- الثكل العام للمبني: \\
\hline
\end{tabular}


Abd- ElHafez, Nabila E.

\begin{tabular}{|c|c|c|}
\hline$\%$ & 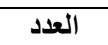 & المواصفات \\
\hline 6.3 & 3 & - مصممة على شكل فيلا. \\
\hline 91.7 & 44 & تتكون من طابق واحد. \\
\hline 2.1 & 1 & تتكون من طابقين. \\
\hline 85.4 & 41 & - - - لمبنى صغير \\
\hline $\begin{array}{c}35.4 \\
100.00\end{array}$ & $\begin{array}{c}\text { تكر ارات } \\
17 \\
48\end{array}$ & ــ ـ المبنى مستقل الأساسي من المبنى: \\
\hline & & 3- وجود سور وألوانه: \\
\hline $\begin{array}{l}70.8 \\
27.1\end{array}$ & $\begin{array}{l}34 \\
13\end{array}$ & 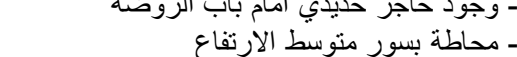 \\
\hline 68.7 & 33 & ـ جدران المبنى ذات ألوان جميلية وز اهية \\
\hline 85.4 & 41 & ـ توجد لافتات محببة للأطفال \\
\hline
\end{tabular}

ثالثا: العناصر الداخلية للمبنى: 1- العجرات د/خل الروضة:

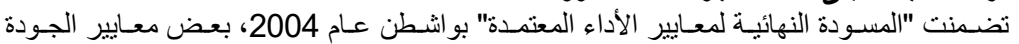

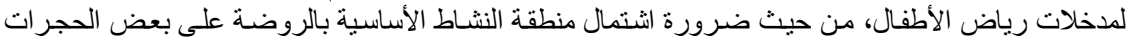

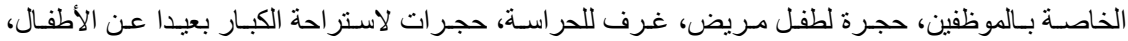

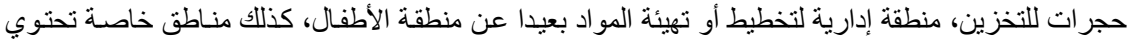

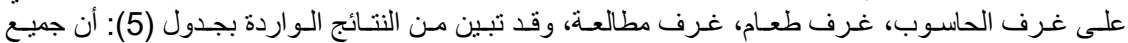

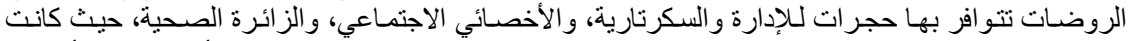

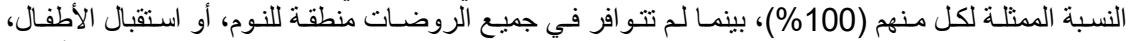

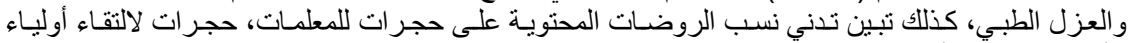

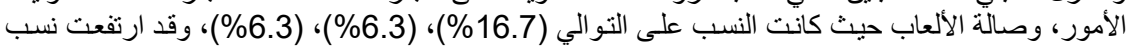

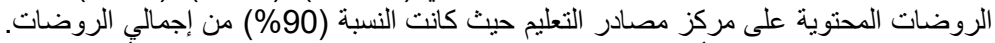

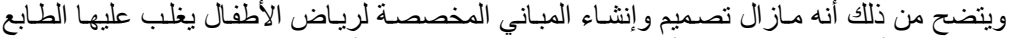

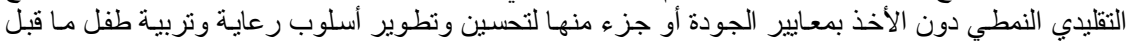

2- مواصفات حجرة النشاط:

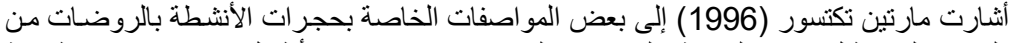

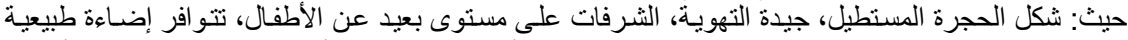

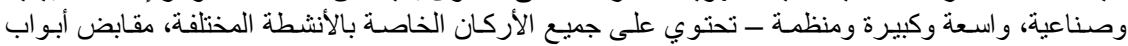

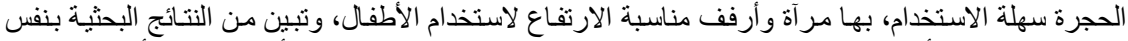

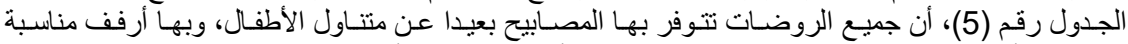

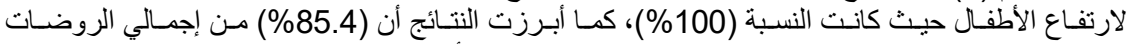

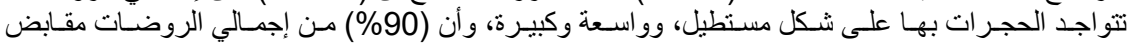

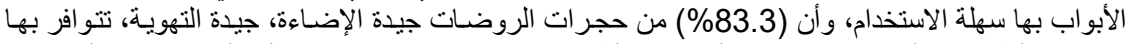

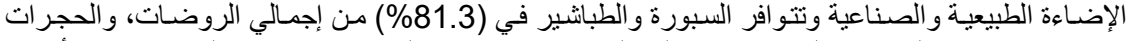

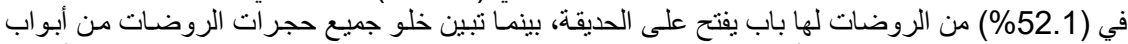

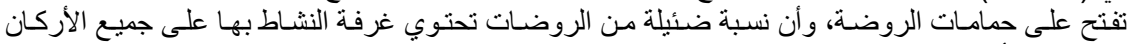

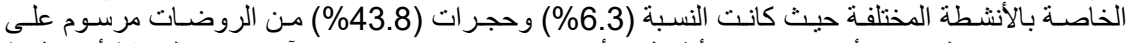

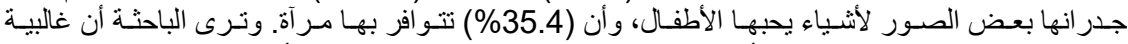

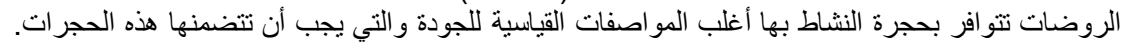

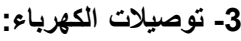

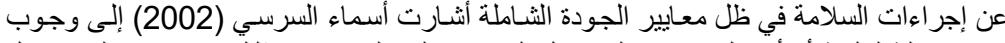

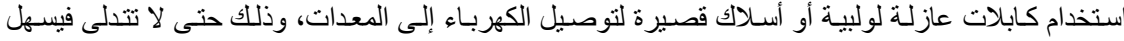

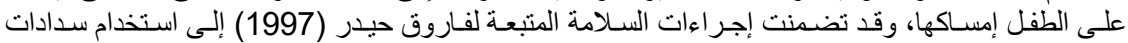
بلاستيكية عازلة لسد المآخذ غير المستخدمة والمنخفضـة والعارية حتى لا يتمكن الطفل من إدخال أشياء بهـا، 


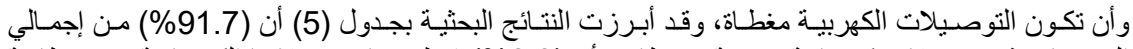

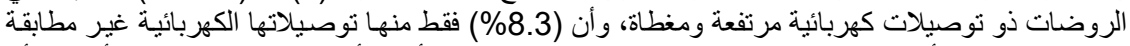

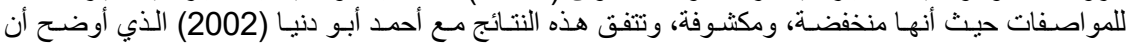

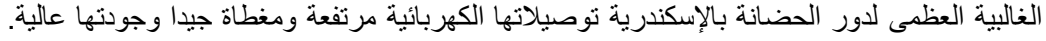

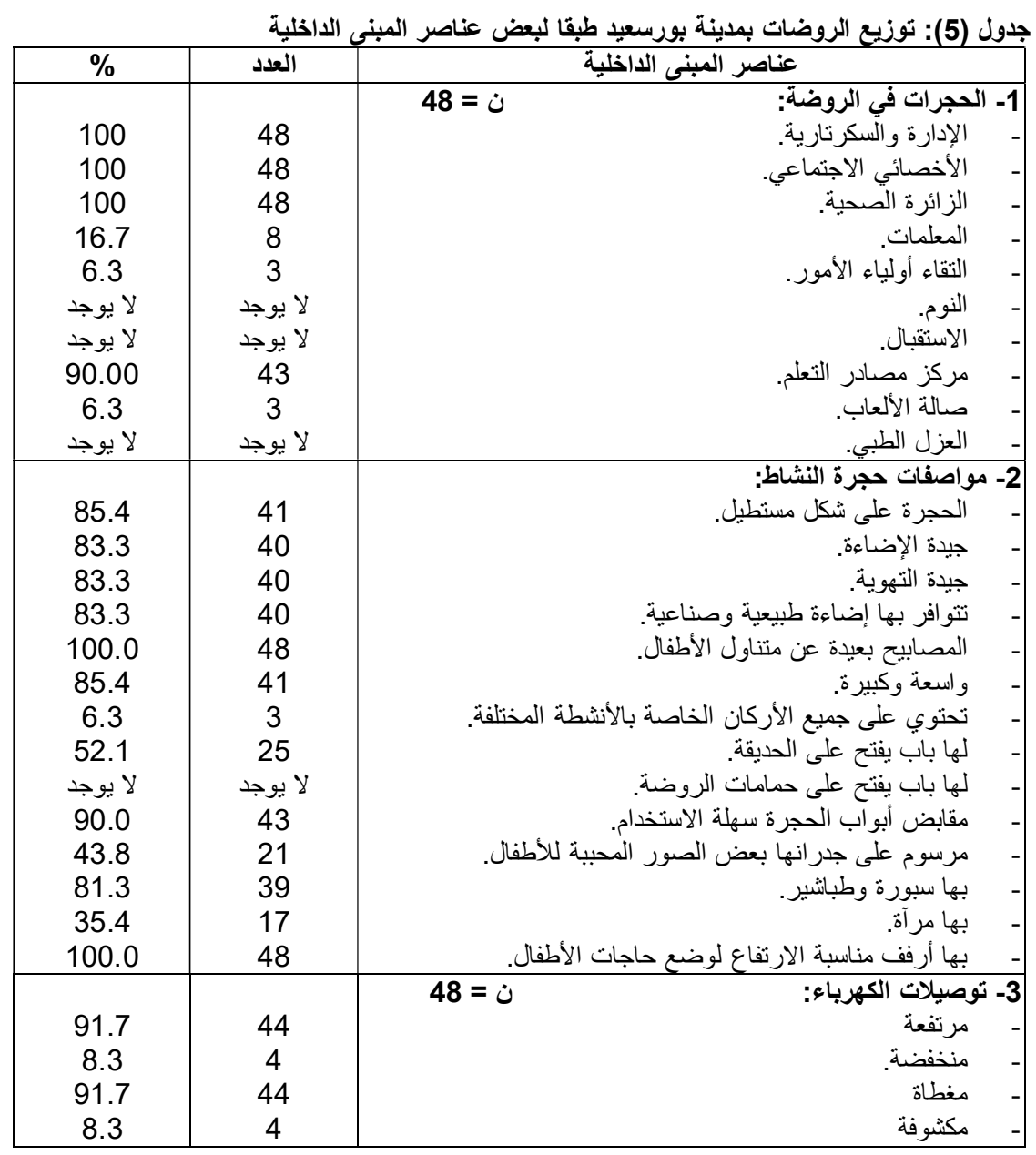

رابعا: بعض العناصر المكملة الملحقة بالمبنى داخليا:

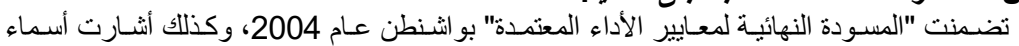

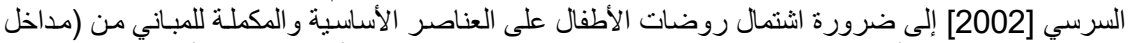
ومخارج للطوارئ، الأبواب، النوافذ السلم) ومعايير تقنية محددة للحفاظ على أمن وسلامة الأطفال.

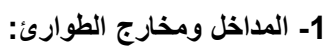

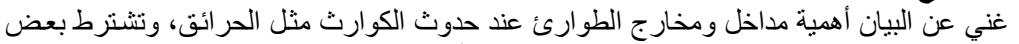

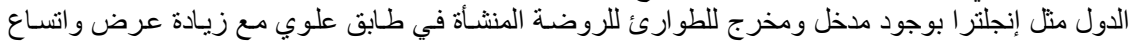


Abd- ElHafez, Nabila E.

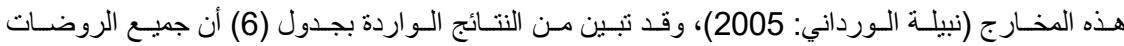

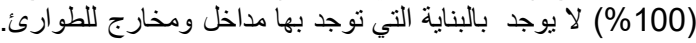

جلول (6): توزيع الروضات بمدينة بورسعيد طبقا لبعض العناصر المكملة الملحقة بالمبنى

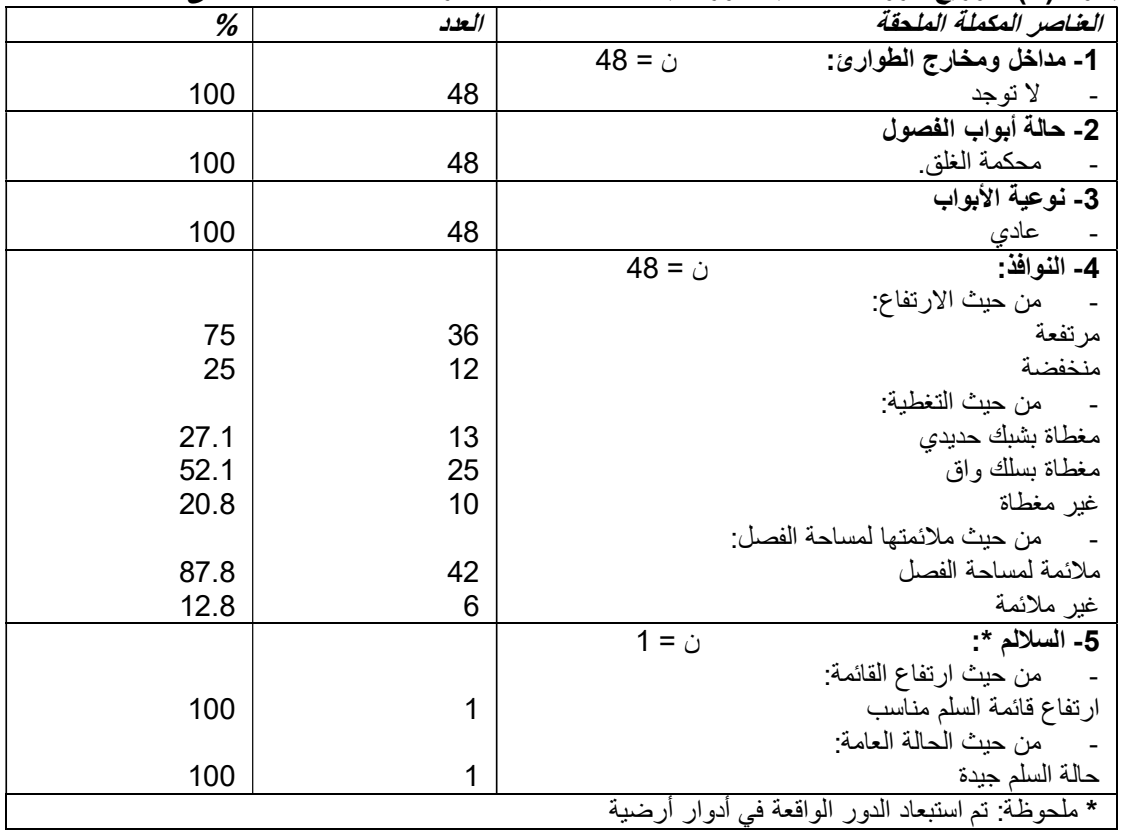

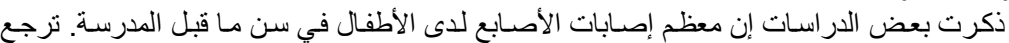

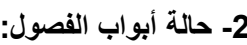

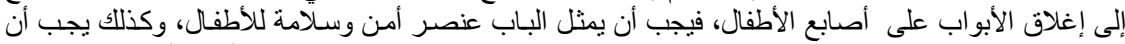

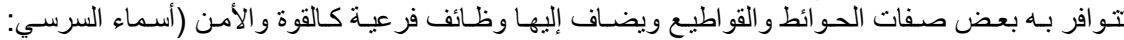
3002)، وقد أوضحت النتائج البحثية بنفس الجدول أن (100 (100) من أبو اب الروضات محكمة الغلق.

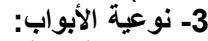

أشثار أحمد أبو دنيا (2002)، أن استخدام الباب المروحة قد يشكل خطورة على الأطفال، وقد تبين

من النتائج أن (100\%) من الروضات ذات ذات أبواب خثبية عادية.

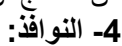

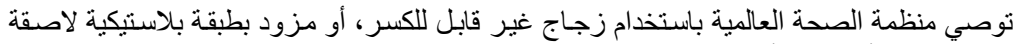

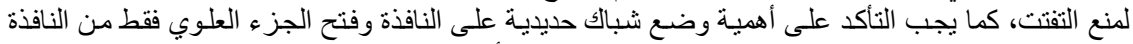

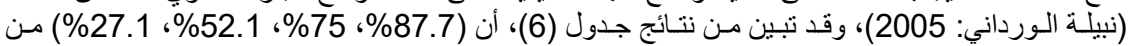

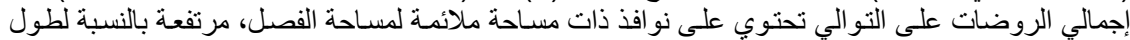

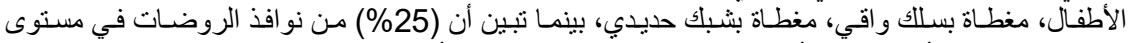

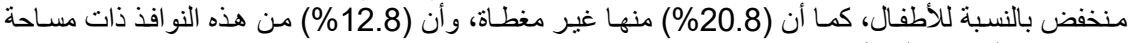
غير ملائمة لمساحة الفصل.

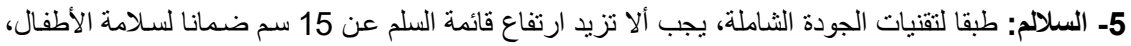

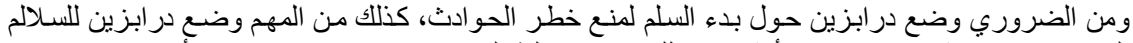

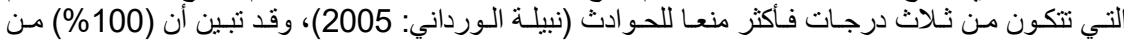

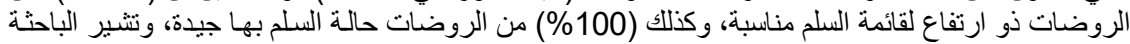


أن جميع السـلالم بهـا در ابزين مناسـ، كمـا تشير إلى عدم وجـود مصــاعد كهربائيسة في أي مس الروضـات خامسا: مواصفات دورات المياه الملحقة بالروضات:

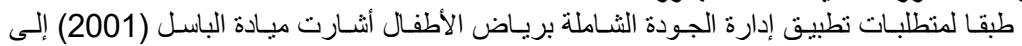

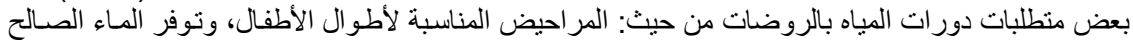

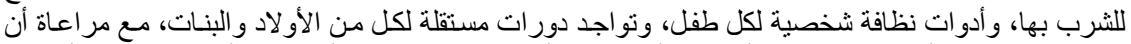

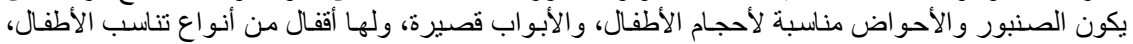

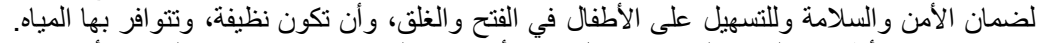

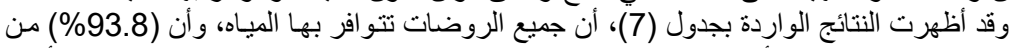

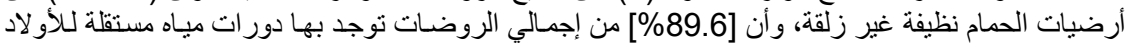

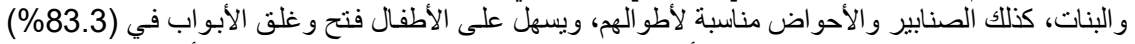

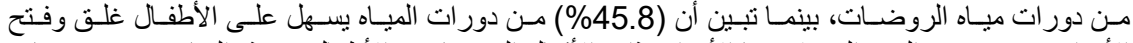

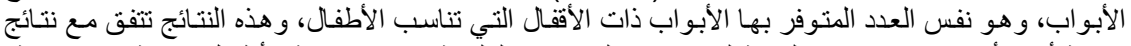

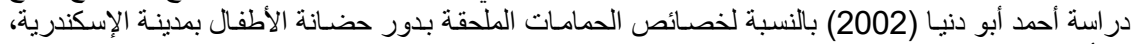

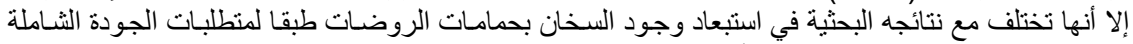
تجنبا لعو امل الخطر من حيث الحرق أو تسرب الخهاد الغاز.

\begin{tabular}{|c|c|c|c|c|}
\hline & \multicolumn{4}{|c|}{ جدول (7): توزيع الروضات بمدينة بورسعيد طبقا لمواصفات دورات المياه } \\
\hline 896 & 43 & $48=$. & تو حد دو ات مستقلة لكل من الأو لاد و النات & 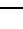 \\
\hline 89.6 & 43 & & الصنبور والأحو اض مناسبة لأطو ال الأطفال & - \\
\hline 45.8 & 22 & & الأبواب قصيرة & - \\
\hline 45.8 & 22 & & الأبواب لها أقفال من أنواع تتاسب الأطفال & - \\
\hline 83.3 & 40 & & فتح و غلق الأبو اب يسهل لَلأطفال التعامل معها & - \\
\hline 93.8 & 45 & & الأرضيات نظيفة غير زلقة & - \\
\hline 100.0 & 48 & & تتو افر بها المياه & - \\
\hline
\end{tabular}

سادسا: مواصفات الأرضيات والأثاث بالروضات:

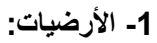

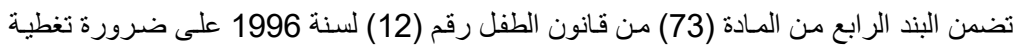

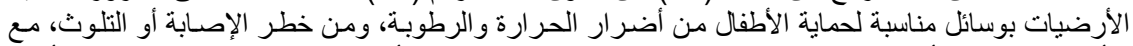

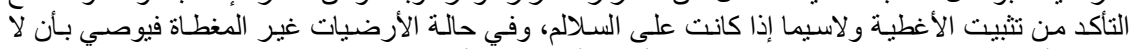

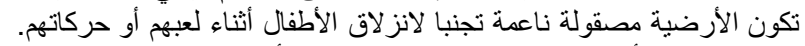

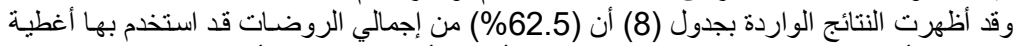

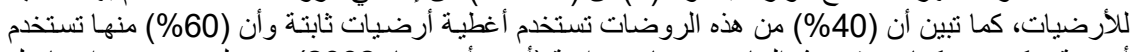

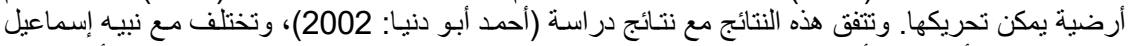

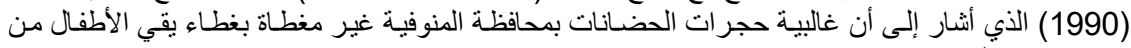

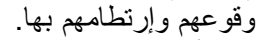

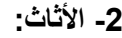

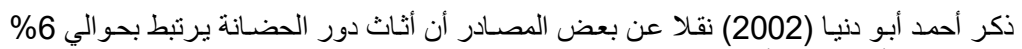

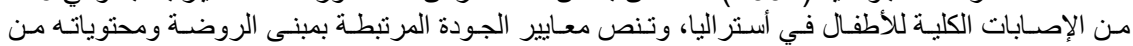

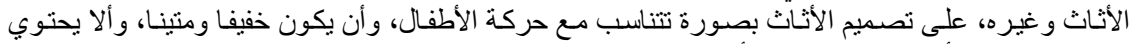
على زو ايا حادة بأبي قطعة من قطع الأثاث.

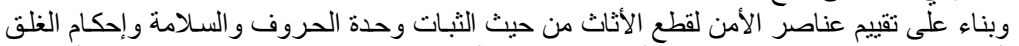

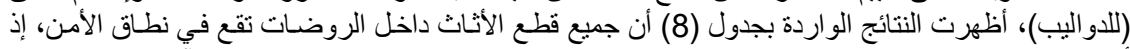

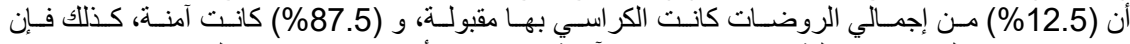

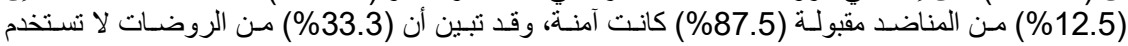

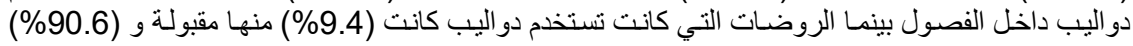


Abd- ElHafez, Nabila E.

منها آمنة، كذلك تبين أن (79.2\%) من الروضات تستخدم أرفف داخل الفصول وقد كان (15.8\%) من هذه الروضات استخدامها مقبول و (84.2\%) منها آمنة.

جدول (8): توزيع الروضات بمدينة بورسعيد وفقا لبعض مواصفات الأرضيات والأثاث

\begin{tabular}{|c|c|c|c|}
\hline$\%$ & العدد & \multicolumn{2}{|c|}{ المواصفات } \\
\hline & & $48-\dot{0}$ & 1- أرضيات الفصول: \\
\hline 62.5 & 30 & & مغطاة \\
\hline 37.5 & 18 & & غير مغطاة \\
\hline 100.0 & 48 & & المجموع \\
\hline & & 30 = & - 2- غطاء الأرضيات: \\
\hline 40 & 12 & & ثابت " \\
\hline 60 & 18 & & متحرك \\
\hline 100 & 30 & & مجموع \\
\hline $\begin{array}{l}12.5 \\
87.5\end{array}$ & $\begin{array}{c}6 \\
42\end{array}$ & 48 = ن & 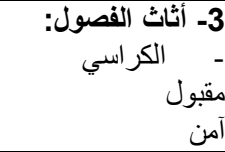 \\
\hline & 48 & & المجموع \\
\hline $\begin{array}{l}12.5 \\
87.5\end{array}$ & $\begin{array}{c}6 \\
42 \\
\end{array}$ & 48 = ن & ـ مقبول المناضد: \\
\hline & 48 & & المجموع \\
\hline $\begin{array}{c}9.4 \\
90.6\end{array}$ & $\begin{array}{c}3 \\
29\end{array}$ & 32 = ن & ـ مقبول الدواليب: \\
\hline 100.0 & 32 & & المجموع \\
\hline $\begin{array}{l}15.8 \\
84.2\end{array}$ & $\begin{array}{c}6 \\
32\end{array}$ & $38=ن$ & مق آمنبول \\
\hline 100.0 & 38 & & مجموع \\
\hline
\end{tabular}

سابعا: مواصفات الحدائق ومحتوياتها:

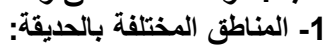

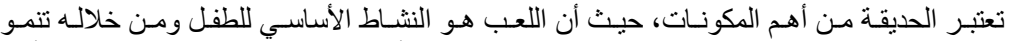

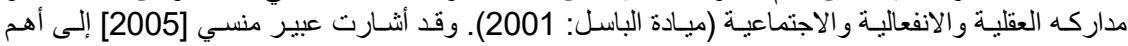

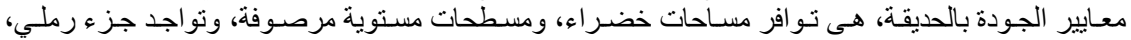

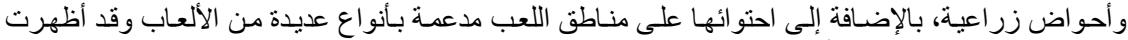

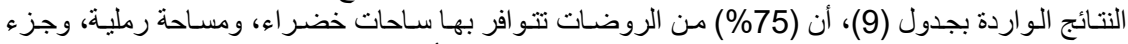

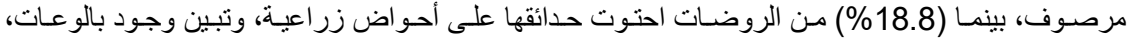
ومناطق ملاعب بنسبة (62.5\%) (18) لكل منها. 2- مواصفات مناطق الملاعب: مناطب

تبين من النتائج البحثية أن جميع الملاعب المنوفرة بالروضة تحتوب على على أركان للتأرجح و التزحلق

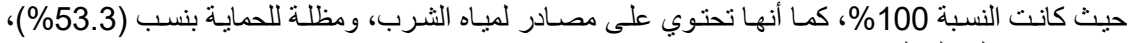

(\%63.3) ( على التوالي. 
تبين أن (83.3\%) مـن الروضـات ذات الملاعب تحتوب ملاعبها على ألعـاب مثل الزحساليق،

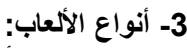

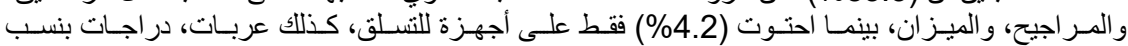

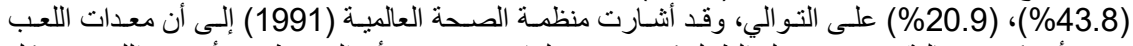

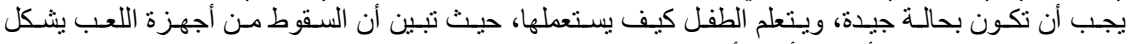
(9.5\%) من إصابات الأطفال (أحمد أبو دنيا: 2002).

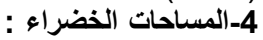

وقد تبين من جدول (9)، أن المساحات الخضر ات قريبة من المساحة الخاصة باللعب (طبقا لأسس الجودة) وذلك في (18.8\%) من إجمالي الروضات.

جدول (9): توزيع الروضات بمدينة بورسعيد طبقا لبعض مواصفات الحدائق ومحتوياتها

\begin{tabular}{|c|c|c|c|c|}
\hline$\%$ & العلد & \multicolumn{3}{|c|}{ المواصفات } \\
\hline & & $48=ن$ & ـ مواصفات المناطق المختلفة بالحايقة: & \\
\hline 75 & 36 & & تو اجد مساحات خضر اء. & - \\
\hline 75 & 36 & & تو اجد جزء رملي. & - \\
\hline 75 & 36 & & تو اجد مسطح مستوى وصلب (مرصوف). & - \\
\hline 18.8 & 9 & & تو اجد أحواض زر اعية. & - \\
\hline 62.5 & 30 & & تو اجد بالو عات. & - \\
\hline 62.5 & 30 & & تو اجد منطقة للملاعب. & - \\
\hline & & $30=ن$ & - مواصفات منطقة الملاعب (اللعب): & \\
\hline 100 & 30 & & تواجد أركان للتارجح و التزحلق. & - \\
\hline 53.3 & 16 & & تو اجد مصادر لمياه الثرب. & - \\
\hline 63.3 & 19 & & تو اجد مظلة للحماية & - \\
\hline & & 48 = ن & ل أنواع الألعاب: & -3 \\
\hline 43.8 & 21 & & عربات. & - \\
\hline 20.9 & 10 & & دراجات. & - \\
\hline 4.2 & 2 & & 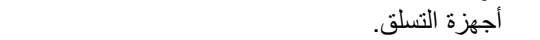 & - \\
\hline 83.3 & 40 & & زحاليق. & - \\
\hline 83.3 & 40 & & 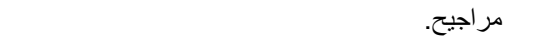 & - \\
\hline 83.3 & 40 & & 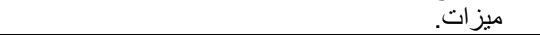 & - \\
\hline 18.8 & 9 & $48=ن$ & ـ المساحات الخضر اء قريبة من المساحة الخاصة باللعب. & \\
\hline 43.8 & 21 & $48=ن$ & ـ بها مدينة مرورية مصغرة. & \\
\hline
\end{tabular}

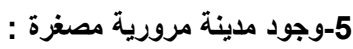

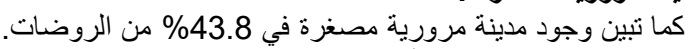

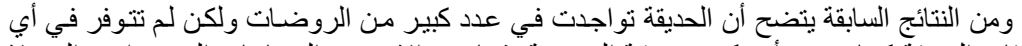

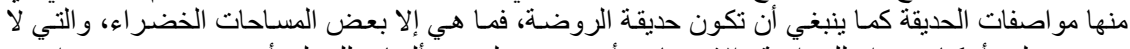

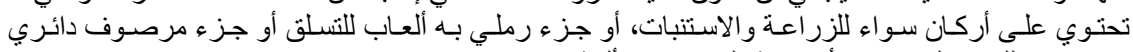

لاستخدامه للعب بالدراجات، أو تربية الحيو انات الأليفة.

مما لاثك فيه أن هذه الدر اسة التي تناولت تقييم بعض مقومات السلامة ـ الخاصة بالبيئة الداخلية التوصيات

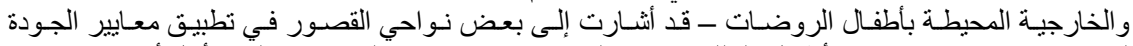

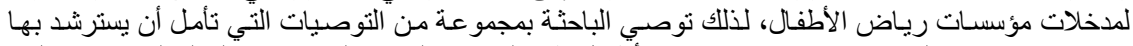

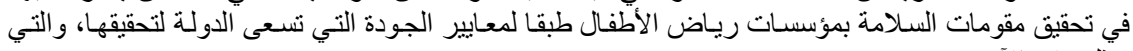

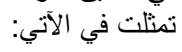


Abd- ElHafez, Nabila E.

1- تنفيذ وتفعيل البرامج التدرييية للعاملين برياض الأطفال و المتضمنة كيفية تهيئة المقومات البيئية المحيطة

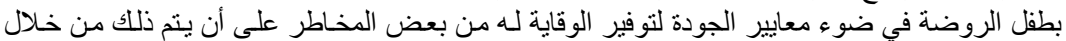

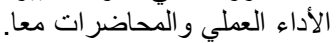

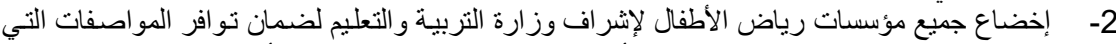

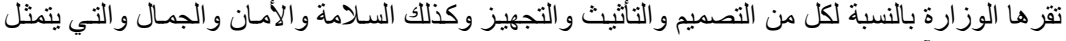

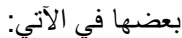

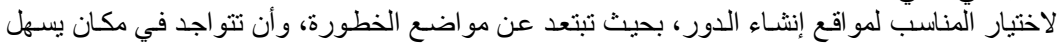

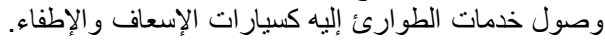

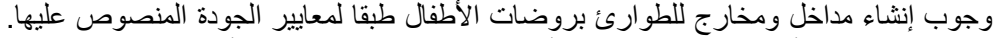

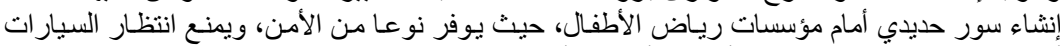

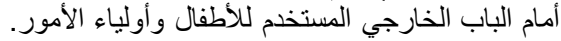

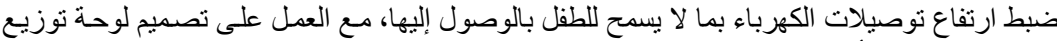

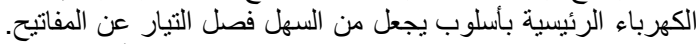

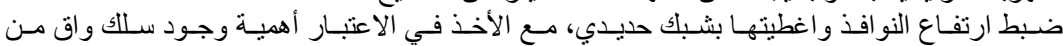

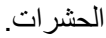

وجوب إنشـاء مظلـة متحركة، للاستفادة من الظل أو أثـعة الثمس غير الضـارة، لاسيما في الملاعب محدودة المساحة. استخدام مواد ماصة للصدمات لأرضيات الملاعب الخارجية منل الرمال أو اللائن.

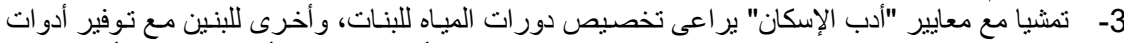

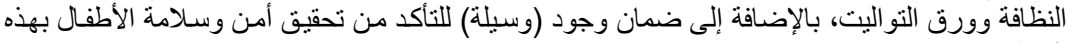

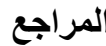

المنطقة

1- أحمد سمير أبو دنيـا (2002): معسارف وممارسـات المشرفات في مجـال الإسـعافات الأوليـة ومقومـات

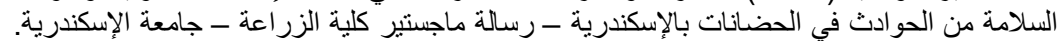

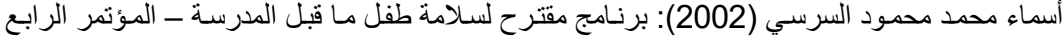
- معهد الدراسات العليا للطفولة - جامعة عين شئمس.

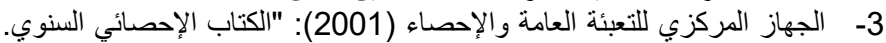

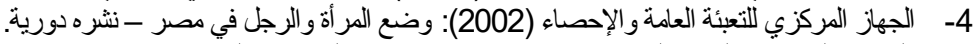

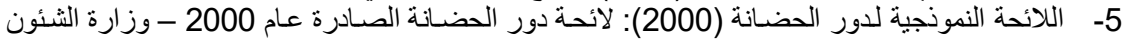
6- أمال راشد نوير (1990): الطفل في الدوريات المصرية ــ الهيئة المصرية العامة للكتاب.

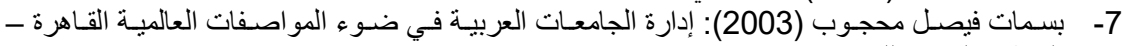
المنظمة العربية للتنمية.

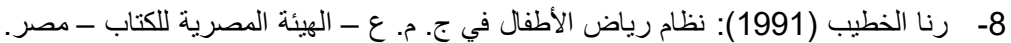

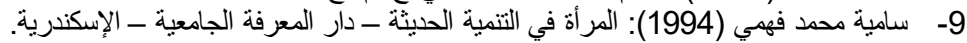

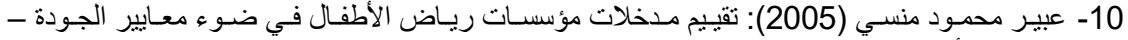
المؤتمر الأول لنوعية بورسعيد - جامعة قلناة السويس.

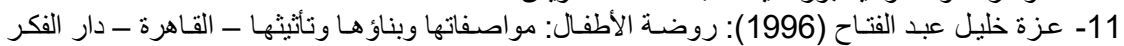
العربي.

12- مارتين تكتسور (1996): إعداد المفاهيم وتطبيق مقاييس الجودة - دورة عن التعليم من 1 - 3 يوليو - مأبو سلطان.

13- محمد يوسف أبو ملوح (2005): مؤشرات الجودة في التعليم - القاهرة المكتبة التجارية الحيثئة.

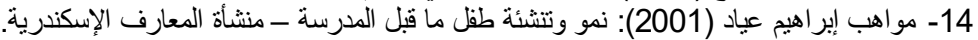

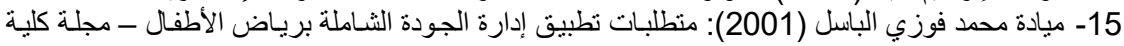

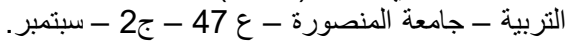

16- نانسي عبد العزيز سليمان (2000): "عالج طفلك حنى يصل الطبيب" - دار أخبار اليوم - مصر. 


$$
\begin{aligned}
& \text { 17- نبيلة الورداني عبد الحافظ (2005): ادارة ريـاض الأطفال ـ كلية التربية النوعية-بورسعيد - جامعة }
\end{aligned}
$$

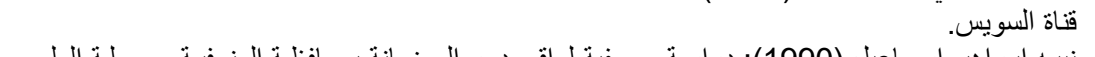

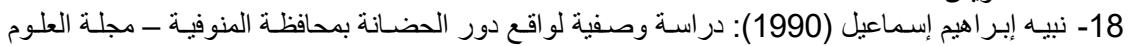

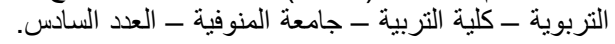

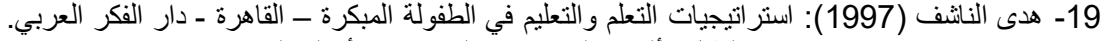

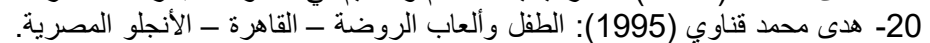

$$
\begin{aligned}
& \text { 21- و واشنطن(2004): تقرير الأمم المتحدة- المسوده العاب الروضهائية لمعايير الأداء المعتمده. }
\end{aligned}
$$

\title{
AN EVALUATION OF SOME ELEMENTS OF SAFETY OF THE INTERNAL AND EXTERNAL ENVIRONMENT IN WHICH CHILDREN IN PORT SAID CITY KINDERGARTENS LIVE IN THE LIGHT OF QUALITY CRITERIA.
}

Abd- ElHafez, Nabila E.

Home and Institution management Dep. Suez Canal University

\begin{abstract}
ABCTRACT
This study took place in order to evaluate the elements of safety of the internal and external environments in which children in Port Said city kindergartens live so that the results of this study could help the officials in charge of the improvement in this stage to achieve the desired quality of safety and security elements in the kindergartens.

Data of this study has been fulfilled by acquiring personal data about (48) kindergartens in Port Said city, Statistical methods used were percentages and frequencies.

Results of this study had indicated that all kindergartens were located in residential areas and were easy to reach, the results also indicated that $(85 \%)$ of kindergartens were near to the institutions where the mothers of the children works and it was also indicated that $(16.7 \%)$ of kindergartens were located in areas near which there were no medical services centers and that $(87.5 \%)$ of the kindergartens were located in wide streets , the results also indicated that $(100 \%, 91.7 \%, 85.4 \%)$ successively of the total member of the kindergartens were attached to schools and consisting of a small building with one floor, whereas in all the kindergartens , there were no places for sleep or receiving children or medically isolated patients.

For safety elements inside the kindergartens, It had been indicated that all kindergartens had lamps which are away from the reach of children, and that the shelves and the handles of the doors were suitable to the height of the children and easy to use and that (91.7\%) of kindergartens had electric sockets which are high and covered with insulators, it was also indicated that all the kindergartens did not have emergency entrances or exits , and that all the kindergartens have stairs in good condition , and that $(89 \%$, $93.8 \%$ ) of the kindergartens successively had toilets floors which had clean and not slippery, it was easy for the children in (45.8\%) of the kindergartens to open and close the toilets doors, (62.2\%) of floors were covered, all
\end{abstract}


Abd- ElHafez, Nabila E.

pieces of furniture in the kindergartens are in the safety range since they are stable , not sharp-edged and safe, $(75 \%)$ of the kindergartens have enough green and sandy areas and pavements , $(62.5 \%)$ of the kindergartens have playgrounds, whereas (18.8\%) of the kindergartens had green areas near to the playgrounds according to quality and safety criteria .

The researcher recommends accelerating the training programs which include children safety and security in the light of quality criteria for those who work for the kindergartens, and rendering all kindergartens institution submissive to the supervision of the ministry of education, forming emergency entrances and exits, and, necessarily assigning separate toilets for both boys and girls in accordance with housing etiquette. 